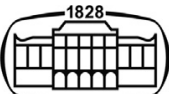

AKADÉMIAI KIADÓ

Journal of Behavioral Addictions

$10(2021) 2,352-360$

DOI:

$10.1556 / 2006.2021 .00026$

(c) 2021 The Author(s)

\title{
Social communication disorder and behavioural addiction: Case report and clinical implications
}

\author{
ELODIE HUREL ${ }^{1,2} \odot$, GAËLLE CHALLET-BOUJU ${ }^{1,2} \odot$, \\ MARION CHIRIO-ESPITALIER ${ }^{1,2}$, MALORY VINCENT ${ }^{1}$ and \\ MARIE GRALL-BRONNEC ${ }^{* 1,2}$
}

\author{
${ }^{1}$ Psychiatry and Mental Health Department, CHU de Nantes, Nantes, France \\ ${ }^{2}$ Université de Nantes, Université de Tours, Inserm U1246, Nantes, France
}

Received: November 20, 2020 • Revised manuscript received: February 11, 2021; March 18, 2021 - Accepted: April 5, 2021

Published online: May 13, 2021
CASE REPORT

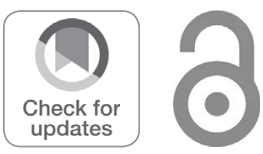

*Corresponding author.

E-mail: marie.bronnec@chu-nantes.fr

\begin{abstract}
Background: Social communication disorder (SCD) is a neurodevelopmental disorder that includes communication difficulties. Literature linking SCD and addictions is scarce, and there are only a few case reports regarding the co-occurrence of addiction and autism disorder spectrum, and only one of them addressed behavioural addictions. Case presentation: We report MC's case, who displayed an SCD and sexual addiction (SA). Clinical and neuropsychological evaluations suggested an alteration of social cognition, especially of affective theory of mind. This article also presents the adaptation made of the usual treatment. Discussion: This case report illustrates the importance of social cognition abilities in the development and maintenance of behavioural addictions, and specifically SA. It also highlights the possible comorbidity of these two disorders and the possibility to work on social cognition as an alternate therapy in the treatment of behavioural addictions. Conclusions: The co-occurrence of SCD and a behavioural addiction triggered clinical adaptations and implications that may affect a patient's treatment presenting one of these disorders.
\end{abstract}

\section{KEYWORDS}

social communication disorder, behavioural addiction, case report, sexual addiction, addictive disorder, neuropsychology

\section{BACKGROUND}

The Diagnostic and Statistical Manual of mental disorders (DSM) newly included social communication disorder (SCD) in its fifth version (American Psychiatry Association, 2013). SCD concerns all patients presenting difficulties in using and understanding verbal and nonverbal communication that alter their daily life, without the presence of a disability or another mental disorder. For example, patients with SCD may experience difficulties using non-literal communication (irony, jokes) or respecting conversation codes. Restrained interests and repetitive behaviours cannot be present; otherwise, difficulties may be classified under autism spectrum disorder (ASD) (Swineford, Thurm, Baird, Wetherby, \& Swedo, 2014). ASD and SCD are both neurodevelopmental disorders that include communication difficulties.

It appears that ASD and addiction can co-occur (10.8\% of the prevalence of internet addiction in an ASD group, So et al., 2017), impacting the treatment. Indeed, as shown by the case report of van Wijngaarden-Cremers and van der Gaag (2015), a deficit in understanding social situations can lead patients to dangerous situations (sexual abuse and addiction to substances in this particular case report) because they attributed good intentions to others. Moreover, the usual treatment can be problematic because of the tendency of patients to interpret everything literally. However, few case reports linking ASD or SCD to addictions 
have been published. To our knowledge, only one of them was about a behavioural addiction (two cases of high functioning autism patients displaying a history of internet gaming addiction coupled with a gambling disorder or excessive sexual activity). The authors did not report any standardized measures (Wong, 2018).

In our case report, we present a co-occurrence between sexual addiction (SA) and SCD. SA is a disorder that still needs further research to be included in the addiction sections of international classifications (Kraus et al., 2018). Nevertheless, compulsive sexual disorder has been added in the 11th of International Classification of Diseases (ICD-11) as an impulse control disorder (see Grubbs et al., 2020, for a history of the evolution of this concept). This diagnostic involves sexual activities being the main interest in the disinvestment of other spheres, a loss of control over the behaviour, and the cessation of sexual behaviour being impossible despite negative consequences and a lack of satisfaction (World Health Organization, 2018).

\section{CASE PRESENTATION}

\section{Presentation of the patient}

The patient gave her written consent for the description of her case. MC is a single 27-year-old woman who met several practitioners during her childhood for motor difficulties and struggles regarding novelty, for which neuroimaging did not show any alterations. After two failures to obtain her high school diploma and complaints regarding spatial orientation and relations to peers, new assessments were made. A genetic exploration highlighted a micro-deletion non-indexed in databases, the pathogenicity of which is uncertain. At the same time, neuropsychological evaluation excluded intellectual disability and showed difficulties in an advanced theory of mind task (the Reading the Mind in the Eyes Test, Baron-Cohen, Wheelwright, Hill, Raste, \& Plumb, 2001). Finally, at the age of 23, MC was diagnosed with SCD rather than ASD by a specialized centre. Indeed, clinicians judged, based on her mother's information and several assessments, that stereotypies and restrained interests were absent from her developmental history.

After failing to obtain her high school diploma, MC began an adapted training to work in a resource centre. She is currently living with her mother. As a teenager, MC had preoccupations regarding sexuality and consulted erotic chat services in parallel with the difficulties presented above. At the beginning of her adulthood, she was registered on several meeting apps. When her mother discovered that MC was displaying a compulsive sexual behaviour, MC had had several sexual partners. She was willing to practice hardcore sex and to be filmed and posted on the internet. When discovering this situation, her mother confiscated her access to the internet. At this time, MC stopped her training.

Given the compulsive sexual behaviour and loss of control displayed byher daughter, MC was brought by her mother to our addictology department to explore an SA. Her complaints included fear of going outside because of what she could do, for example meeting new men via applications, or whom she could meet and difficulty distinguishing between men with good or bad intentions. Moreover, MC considerably doubted her ability to understand social relationships, and she addressed several letters to clinicians in this perspective.

\section{Diagnostic assessment}

As per the procedure in our department for all patients seeking treatment for a potential behavioural addiction, $\mathrm{MC}$ met the research team for a complete clinical evaluation in the framework of the EVALADD cohort (NCT01248767) (see Table 1 for results and Fig. 1 for the timeline).

The patient met the diagnostic criteria for SA. Moreover, the clinical assessment highlighted (i) the presence of an attention-deficit/hyperactivity disorder (ADHD), (ii) a high level of impulsivity, and (iii) a lack of self-esteem. Nevertheless, considering the clinical characteristics observed as the high level of impulsivity and difficulties encountered with social relationships, we chose to propose a neuropsychological assessment to objectify the patient's subjective information (see Table 2 for results).

This neuropsychological assessment showed that cognitive functioning was globally preserved (speed processing, verbal quotient, visuospatial abilities, and inhibition). Attention assessment showed a meticulous profile that can be linked with the patient's need to have precise answers regarding global social situations. This result also casts doubt on the diagnosis of ADHD identified with self-reports. Furthermore, the evaluation of social cognition did not show a deficit on every test, and MC succeeded in several tasks (emotion recognition, emotional fluencies, and cognitive theory of mind (i.e. attribution of mental states that are not emotions, such as beliefs)) (Shamay-Tsoory \& AharonPeretz, 2007). Nevertheless, she failed the Eyes Test, the Faux Pas Task, and the LEAS (Levels of Emotional Awareness Scale). The Eyes Test is an advanced task for assessing the theory of mind because only eyes are presented, and the related emotions are not basic ones (unlike the emotion recognition task, which was successfully completed by MC). MC failed to recognize a faux pas situation during the test (which made her lose 6 points), and she also did not correctly answer 3 questions about the intentionality of the character and 2 questions regarding emotion attribution. Finally, during the LEAS, MC had difficulties answering questions about her feelings and could not answer questions about others' feelings. These results showed an alteration of the theory of mind, specifically for the emotional component. These outcomes specified the difficulties verbalized by $\mathrm{MC}$ in understanding the intentions of others.

\section{Therapeutic intervention}

MC went to addiction consultations once a month to every two months for the management of her problematic sexual behaviours (see Fig. 1 for the timeline). The patient also had two sexology consultations in our department. Moreover, we decided to deviate from the usual treatment, a cognitive 
Table 1. Clinical evaluation at the first visit

\begin{tabular}{|c|c|}
\hline Pathology explored & Measures \\
\hline \multicolumn{2}{|c|}{ Psychopathological characteristics } \\
\hline Axis 1 Psychiatric disorders & $\begin{array}{l}\text { Mini-International } \\
\text { Neuropsychiatric Interview } \\
\text { (MINI) version } 5.0 \text { adapted for } \\
\text { DSM-5 criteria Lecrubier et al. } \\
\text { (1997) }\end{array}$ \\
\hline $\begin{array}{l}\text { Attention-Deficit/Hyperactivity } \\
\text { Disorder (ADHD) }\end{array}$ & $\begin{array}{l}\text { Wender Utah Rating Scale for } \\
\text { Attention-Deficit/Hyperactivity } \\
\text { Disorder in Adults (WURS-C) } \\
\text { (Ward, Wender, \& Reimherr, } \\
\text { 1993) } \\
\text { Adult ADHD Self-Report Scale } \\
\text { (ASRS-1.1) (Kessler et al., 2005) }\end{array}$ \\
\hline
\end{tabular}

Personality characteristics

Attachment style

Impulsivity

Personality

\section{Self-esteem}

Quality of life

Sexual addiction characteristics

Rosenberg Self-Esteem Scale (RSES) (Rosenberg, 2015) Satisfaction with Life Scale (SWLS) (Diener, Emmons, Larsen, \& Griffin, 1985) Inventory (TCI-125)

(Cloninger, Svrakic, \& Przybeck, 1993)

Face-to-face interview exploring the diagnosis criteria proposed by Carnes and following the structure of the NODS (National Opinion Research Center DSM Screen for Gambling Problems) (Carnes, 2001; Carnes, Hopkins, \& Green, 2014)

Goodman criteria for Sexual Addiction (Goodman, 2001) Sexual Addiction Screening Test-Revised (SAST-R) (Carnes, Green, \& Carnes, 2010)

Results

\section{Positive diagnosis}

Major depressive

episode

Suicidal risk

Social phobia

Post-traumatic stress

disorder

$86 / 100$

(cut-off for the diagnostic: score $\geq 46$ )

$5 / 6$ (cut-off for the diagnostic is a score $\geq 4$ )

Attention deficit: $33 / 36$

Hyperactivity: 27/36

\section{Secure: $2.6 / 5$}

Fearful: $2.4 / 5$

Preoccupied: $3.4 / 5$

Dismissing: $3.4 / 5$

Negative urgency: $14 / 16$

Positive urgency: 10/16

Lack of premeditation: 11/16

Lack of perseverance: $8 / 16$

Sensation seeking: 15/16

Temperaments:

Novelty seeking: $45 / 100$

Harm avoidance: $85 / 100$

Reward dependence: 80/100

Persistence: 80/100

Characters:

Self-directedness: $36 / 100$

Cooperativeness: 60/100

Self-transcendence: $33.3 / 100$

19/40 (low)

$17 / 35$ (slightly below the mean)

Exploration of the period before the cessation of the problematic behaviour: score $=7 / 10$ (cut-off score $\geq 3$ )
Core item scale: $14 / 20$ (cut-off is a score $\geq 6$ )

Internet items: $4 / 6$ (cut-off is a score $\geq 3$ )

Men's items: $\mathbf{2} / 6$ (cut-off is a score $\geq 2$ )

Women's items: $\mathbf{2} / 6$ (three item missing, the cut-off is a score $\geq 2$ ) Homosexuality items: $\mathbf{5 / 6}$ (one item missing, cut-off is a score $\geq 3$ ) 
Table 1. Continued

\begin{tabular}{ll}
\hline Pathology explored & Results \\
\hline & Preoccupation: $2 / 4$ (cut-off is score $\geq 2$ ) \\
& Loss of control: $4 / 4$ (cut-off is score $\geq 2)$ \\
& Relationship disturbance: $4 / 4$ (cut-off is score $\geq 2$ ) \\
Factors triggering problematic & Affect disturbance: $3 / 5$ (cut-off is score $\geq 2$ ) \\
behaviour & Difficulties in relationships: $10 / 10$ \\
& Feeling positive emotions: $0 / 10$ \\
& Feeling negative emotions: $9 / 10$ \\
& Financial problems: $0 / 10$ \\
& Cash inflow: $0 / 10$ \\
& Context (place, people): $7 / 10$ \\
& Publicity: $8 / 10$ \\
& Substance use: $0 / 10$ \\
\hline
\end{tabular}

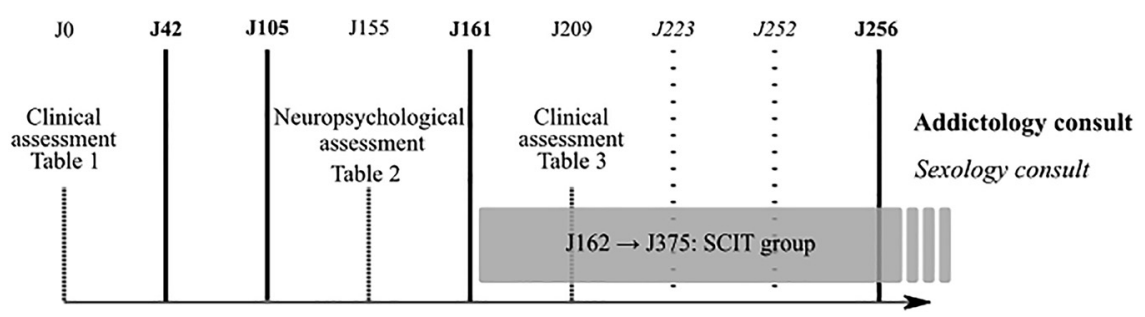

Fig. 1. Timeline of the treatment of the patient

behavioural therapy (CBT) group. We created 10 years ago this CBT program dedicated to outpatients with a sex addiction. This program consists of 10 weekly sessions lasting about 2 hours each, and involves 2 therapists for 10 patients. It aims at training to train patients throughout CBT strategies to regain control over sex behaviour. It combines motivational interviewing, psychoeducation regarding sex addiction and adaptive sexuality, stimulus control and response prevention strategies, cognitive restructuring, and relapse prevention techniques. However, the patient was included in a social cognition and interaction training (SCIT, Combs et al., 2009) group. This therapeutic group, initially created for patients with schizophrenic disorders, consists of 24 weekly sessions of 1 hour 30 minutes and is focused on emotion perception, attribution style, and theory of mind. Its objective is to improve social cognition abilities and decrease socialcognitive biases in order to improve social functioning (Roberts et al., 2014). We chose to include her in this group, composed of patients with schizophrenia who also display alterations in social cognition, because, even if it took the appearance of SA, the observed problematic sexual behaviour was also, in our opinion, the reflection of social cognitive difficulties. This type of group does not require strong empathy skills, reading social cues, or interacting efficiently, as is the case for CBT groups, and it maintains the advantage of a collective format and an opportunity to practise social skills. No medication was added to the treatment.

\section{Follow-up and outcomes}

After six months of treatment, MC did not show SA's criteria (see Table 3 for the follow-up clinical evaluation). Nevertheless,
MC was still questioning social norms and tried to understand the implicit rules of social relationships. The patient also felt that the situation was a dead end. Regarding the SCIT group, her mother, who took the role of practice partner (i.e. the identified person who works with the patient during the week on SCIT exercises), related that the group was an excellent socialisation exercise for her daughter. She also noticed that MC was less in her bubble and more aware of the difficulties that other patients could meet. This improvement seems to reflect social cognitive abilities enhancement thanks to the group situation and exercises proposed in the SCIT group.

\section{Patient perspective}

After her treatment, MC noticed an easier processing of emotions, as well as a better understanding of certain social norms. Nevertheless, implicit information was still complex for her to understand.

\section{DISCUSSION}

This case report shows the importance of taking into account social cognition in treating patients with behavioural addictions and, more specifically, SA. Indeed, in MC's case, social cognitive alterations in the framework of her SCD led her to misunderstand certain social situations and accept several risky sexual situations without protecting herself. Nevertheless, our patient also displayed clinical signs of addiction, such as craving and the urge to perform the behaviour, which seemed to indicate that the sexual situations were not only abuses of her vulnerability. For the 
Table 2. Neurocognitive assessment

\begin{tabular}{ll}
\hline Cognitive domain explored & \multicolumn{1}{c}{ Measures } \\
\hline $\begin{array}{l}\text { Processing speed (WAIS-4) } \\
\text { (Wechsler, 2011) }\end{array}$ & Code \\
& Symbols \\
Premorbid intelligence & French version of the National \\
& Adult Reading Test (fNART) \\
& (Mackinnon \& Mulligan, 2005) \\
Visuospatial abilities & Taylor Complex Figure (Taylor, \\
& 1959) \\
& Visual Object and Space \\
& Perception Battery (VOSP) \\
& (Warrington \& James, 1991)
\end{tabular}

Flexibility

PEGV (Protocole Montréal

Toulouse d'Evaluation des

Gnosies visuelles, a protocol that permits the evaluation of visual gnosis) (Agniel et al., 1992)

Trail Making Test (TMT) (Lezak, Howieson, Loring, Hannay, \& Fischer, 2004)

Inhibition

Visual selective attention

Social cognition
Stroop test (Godefroy \& GREFEX, 2008)

D2 test (Zimmermann \& Fimm, 2002)

Facial Emotion Recognition (miniSEA) (Ehrlé, Henry, Pesa, \& Bakchine, 2011)

Faces Test (Etchepare et al., 2014)

Eyes Test (Baron-Cohen et al., 2001)

Emotional fluences

False beliefs (TOM-15)

(Desgranges et al., 2012)

Results

$\begin{array}{lc}67, \mathrm{NS}=8 & \text { Index of processing } \\ 30, \mathrm{NS}=8 & \text { speed: } 89, \\ & \text { percentile } 23\end{array}$

$23 / 40, z=103$, verbal quotient $=102$

$36 / 36$, type 1

Object perception

Incomplete letters: 20/20

Silhouettes: $21 / 30$

Object decision: 12/20 (cut-off $=14)$

Progressive silhouettes: $14 / 20$ (cut-off $=15$ )

Spatial perception

Dot counting: 10/10

Position discrimination: 20/20

Number location: $10 / 10$

Cube analysis tests: $10 / 10$

$20 / 20$

A: $42 \mathrm{~s}, \mathrm{~B}: 94 \mathrm{~s}$; delta $=52 \mathrm{~s}$, percentile $5-10$

Denomination: $61 \mathrm{~s}$, percentile 25

Read: $45 \mathrm{~s}$, percentile 25

Interference: $89 \mathrm{~s}$, percentile 50

Delta: 28 , percentile $50-75$

Number of items processed: GZ: 367, Meticulous

Q1e* profile

Number of error $=1$, percentage of error $\mathrm{F} \%=0.3, \mathbf{Q} 1 \mathbf{e}$

Number of correct $\mathrm{d}^{2}$ crossed,

$\mathrm{KL}=155, \mathrm{Q} 1$

31/35 (loses 1 point for fear, disgust, neutral and anger), $\mathrm{z}=-0.3$

Denomination without clues: $4 / 10$ simple emotions, $2 / 10$ complex ones. Total: $6 / 20: \mathrm{z}=-1.1$

Fixed choice: $8 / 10$ on simple emotions, $10 / 10$ on complex ones

16/36: $\mathrm{z}=-3.25$

The patient always chose the hostile item when proposed. 18 words (completed right after Faces Test; the patient was cued)

1st order: 8/8 FC1, $16 \mathrm{~min}$

$2^{\text {nd }}$ order $5 / 7,6 \mathrm{~min}$

Control questions: 15/15, 2

minutes $19 \mathrm{~s}$
Total $=13 / 15$ $\mathrm{z}=-1.1$

The patient relied on the logic of the story and intellectualized answers, going against her spontaneous choice.

(continued) 
Table 2. Continued

\begin{tabular}{|c|c|c|}
\hline Cognitive domain explored & Measures & Results \\
\hline & $\begin{array}{l}\text { Attribution intention (Brunet, } \\
\text { Sarfati, \& Hardy-Baylé, 2003) }\end{array}$ & $\begin{array}{l}12 \text { good answers, } 1 \text { absurd and } 1 \text { possible } \\
\text { Control questions: } 27 / 28\end{array}$ \\
\hline & $\begin{array}{l}\text { Faux pas (theory of mind, mini } \\
\text { SEA) (Bertoux et al., 2012) }\end{array}$ & $\begin{array}{l}\text { 19/30 Detection of faux pas } \quad z=-\mathbf{1 . 5 5} \\
20 / 20 \text { non-faux pas stories } \\
10 / 10 \text { control questions }\end{array}$ \\
\hline & $\begin{array}{l}\text { LEAS (Levels of Emotional } \\
\text { Awareness Scale) (Bydlowski, } \\
\text { Corcos, Paterniti, Guilbaud, \& } \\
\text { Jeammet, 2002) }\end{array}$ & $\begin{array}{l}\text { Points for feelings of the patient: } 37, \mathrm{z}=\mathbf{- 3 . 4 5} \\
\text { No answer was given regarding the others' feelings }\end{array}$ \\
\hline & $\begin{array}{l}\text { Alexithymia (TAS-20) (Loas, } \\
\text { Fremaux, \& Marchand, 1995) }\end{array}$ & 78 (cut-off is a score $\geq 56$ ) \\
\hline
\end{tabular}

${ }^{*} \mathrm{Q} 1 \mathrm{e}=$ Extreme first quartile.

Table 3. Clinical evaluation after 6 months of treatment

\begin{tabular}{|c|c|c|c|}
\hline Pathology explored & Tool used & Results & $\begin{array}{l}\text { Comparison with the first } \\
\text { assessment }\end{array}$ \\
\hline \multicolumn{4}{|l|}{ Psychopathological characteristics } \\
\hline $\begin{array}{l}\text { Attention-Deficit/Hyperactivity } \\
\text { Disorder }\end{array}$ & $\begin{array}{l}\text { Adult ADHD Self-Report Scale } \\
\text { (ASRS-1.1) }\end{array}$ & $\begin{array}{l}4 \text { items with missing data on the } \\
\text { six first items } \\
\text { Attention deficit: } 18 / 32(4 \\
\text { missing data) } \\
\text { Hyperactivity: } 25 / 36\end{array}$ & $\begin{array}{l}\text { Diminution on both scales, } \\
\text { especially on the attention defici } \\
\text { scale }\end{array}$ \\
\hline \multicolumn{4}{|l|}{ Personality characteristics } \\
\hline Attachment style & $\begin{array}{l}\text { Relationship Scales } \\
\text { Questionnaire (RS-Q) }\end{array}$ & $\begin{array}{l}\text { Secure: } 2.4 / 5 \\
\text { Fearful: NK/5 } \\
\text { Preoccupied: NK/5 } \\
\text { Dismissing: NK/5 }\end{array}$ & $\begin{array}{l}\text { Slight diminution on the secure } \\
\text { scale }\end{array}$ \\
\hline Impulsivity & $\begin{array}{l}\text { Impulsive Behavior Scale } \\
\text { (UPPS-P) }\end{array}$ & $\begin{array}{l}\text { Negative urgency: } 12 / 16 \\
\text { Positive urgency: } 10 / 16 \\
\text { Lack of premedication: NK/16 } \\
\text { Lack of perseveration: } 8 / 16 \\
\text { Sensation seeking: } 8 / 16\end{array}$ & $\begin{array}{l}\text { Diminution of scales regarding } \\
\text { negative urgency and sensation } \\
\text { seeking }\end{array}$ \\
\hline Personality & $\begin{array}{l}\text { Temperament and Character } \\
\text { Inventory (TCI-125) }\end{array}$ & $\begin{array}{l}\text { Characters: } \\
\text { Self-directedness: NK/100 } \\
\text { Cooperativeness: NK100 } \\
\text { Self-transcendence: NK/100 }\end{array}$ & \\
\hline Self-esteem & $\begin{array}{l}\text { Rosenberg Self-Esteem Scale } \\
\text { (RSES) }\end{array}$ & $18 / 40$ (low) & $\begin{array}{l}\text { Decrease of one point, no } \\
\text { improvement in self-esteem }\end{array}$ \\
\hline Quality of life & $\begin{array}{l}\text { Satisfaction with Life Scale } \\
\text { (SWLS) }\end{array}$ & $\begin{array}{l}\text { One missing item } \\
12 / 28 \text { (slightly below the mean) }\end{array}$ & $\begin{array}{l}\text { No significant change of } \\
\text { satisfaction with life }\end{array}$ \\
\hline Sexual addiction characteristics & $\begin{array}{l}\text { Face-to-face interview exploring } \\
\text { the diagnosis criteria proposed } \\
\text { by Carnes and following the } \\
\text { structure of the NODS (National } \\
\text { Opinion Research Center DSM } \\
\text { Screen for Gambling Problems) } \\
\text { Goodman criteria: }\end{array}$ & $\begin{array}{l}\text { Exploration of the actual period: } \\
\text { score }=1 / 10 \text { (cut-off score } \geq 3 \text { ) }\end{array}$ & $\begin{array}{l}\text { Absence of sexual addiction } \\
\text { diagnostic }\end{array}$ \\
\hline & $\begin{array}{l}\text { Sexual Addiction Screening } \\
\text { Test-Revised (SAST-R) }\end{array}$ & $\begin{array}{l}\text { Core item scale: } 10 / 20 \text { (cut-off is } \\
\text { a score } \geq 6 \text { ) } \\
\text { Internet items: } 1 / 6 \text { (one item } \\
\text { missing, cut-off is a score } \geq 3 \text { ) } \\
\text { Men's items: } 0 / 6 \text { (cut-off is a } \\
\text { score } \geq 2 \text { ) } \\
\text { Women's items: } 0 / 6 \text { (one } \\
\text { missing item, cut-off is a score } \\
\geq 2 \text { ) }\end{array}$ & $\begin{array}{l}\text { Improvement of addictive } \\
\text { symptoms }\end{array}$ \\
\hline
\end{tabular}


Table 3. Continued

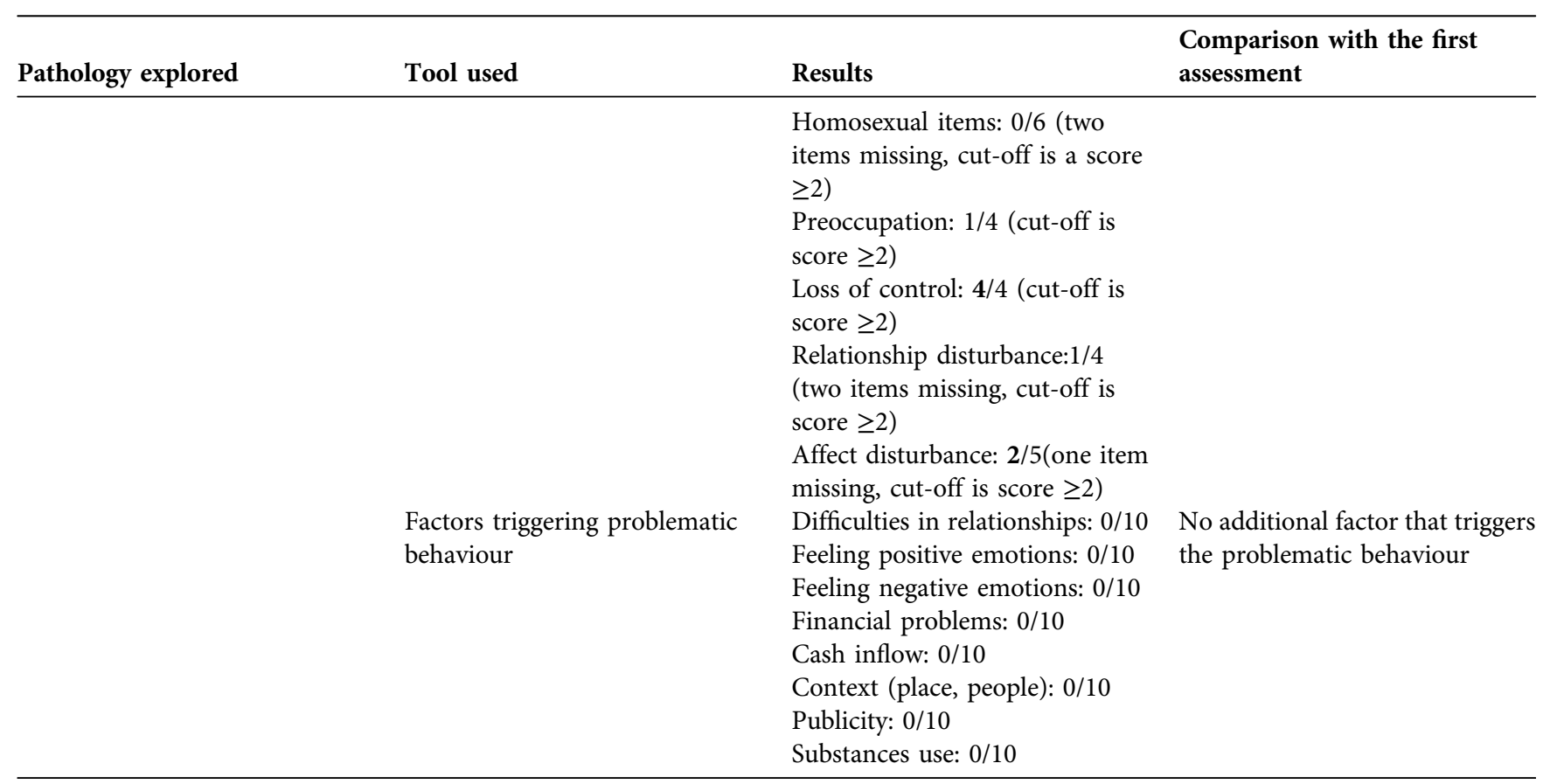

specific case of MC, the SCD may have favoured the appearance and maintenance of SA. Moreover, as the standard treatment for SA (CBT group) could not be proposed to $\mathrm{MC}$, the therapeutic strategy was to work on social cognition. This upstream focus permitted us to work on social abilities, which led her to better understand other's intentions (thanks, for example, to the theory of mind and emotion perception exercises). This helped her protect herself, thanks to a better understanding of situations that can be dangerous.

This case also suggests commune alterations between SCD and addiction. Indeed, MC's neuropsychological assessment identified an alteration of affective theory of mind, which relies on the ventromedial prefrontal cortex (Shamay-Tsoory \& Aharon-Peretz, 2007). This part of the prefrontal cortex has also been linked to hot executive functioning and decision-making in addiction models (Noel, Brevers, \& Bechara, 2013). Therefore, it seems that common neurobiological alterations could explain the comorbidity observed in this case report. Thus, it seems essential to screen for social cognitive disabilities in patients who present addiction and complain of social difficulties. Indeed, even if there is no formal deficit in social communication, therapy focused on the remediation of social cognition could be a therapeutic alternative that can also improve addictive symptoms.

\section{CONCLUSION}

This case report highlights the importance of social cognition abilities in the initiation, development, and maintenance of addictive behaviours. It also shows the link between addiction and social cognition alterations and the importance of assessing patients' social cognition with addictions and clinical signs of addiction for patients presenting alterations of social cognition.

Funding sources: EH has received a Ph.D. sponsorship from the University of Nantes.

Author's contribution: $\mathrm{EH}, \mathrm{MGB}, \mathrm{GCB}$, and MCE are responsible for the conceptualization of the article. MV performed the neuropsychological evaluation. $\mathrm{EH}$ wrote the original draft, and MGB, MCE, MV, and GCB reviewed and edited the paper.

Conflict of interest: The authors declare no conflicts of interest.

Acknowledgements: We would like to thank the CRESERC service of CHU of Nantes, especially Marine Sinquin, the peer support worker, and Delphine Ricci-Lemagnen and her team, who agreed to open their SCIT group. We would also like to thank Elsa Thiabaud and Anaïs Saillard from the research team, who performed clinical assessments.

\section{REFERENCES}

Agniel, A., Joanette, Y., Doyon, B., \& Duchein, C. (1992). Protocole Montréal-Toulouse d'évaluation des gnosies visuelles. L'OrthoÉdition. France.

American Psychiatry Association (2013). DSM-5: Diagnostic and statistical manual of mental disorders. Washington, DC: American Psychiatric Publishing. 
Baron-Cohen, S., Wheelwright, S., Hill, J., Raste, Y., \& Plumb, I. (2001). The "reading the mind in the eyes" test revised version: A study with normal adults, and adults with asperger syndrome or high-functioning autism. Journal of Child Psychology and Psychiatry, 42(2), 241-251. https://doi.org/10.1111/1469-7610. 00715.

Bertoux, M., Delavest, M., de Souza, L. C., Funkiewiez, A., Lépine, J.-P., Fossati, P., et al. (2012). Social cognition and emotional assessment differentiates frontotemporal dementia from depression. Journal of Neurology, Neurosurgery, and Psychiatry, 83(4), 411-416. https://doi.org/10.1136/jnnp-2011-301849.

Brunet, E., Sarfati, Y., \& Hardy-Baylé, M.-C. (2003). Reasoning about physical causality and other's intentions in schizophrenia. Cognitive Neuropsychiatry, 8(2), 129-139. https://doi.org/10. 1080/13546800244000256.

Bydlowski, S., Corcos, M., Paterniti, S., Guilbaud, O., Jeammet, P., \& Consoli, S. M. (2002). French validation study of the levels of emotional awareness scale. L'Encephale, 28(4), 310-320. ENC09-2002-28-4-0013-7006-101019-ART5.

Carnes, P. (2001). Out of the shadows (3rd ed.) Hazelden Publishing.

Carnes, P., Green, B., \& Carnes, S. (2010). The same yet different: Refocusing the sexual addiction screening test (SAST) to reflect orientation and gender. Sexual Addiction \& Compulsivity, 17(1), 7-30. https://doi.org/10.1080/10720161003604087.

Carnes, P. J., Hopkins, T. A., \& Green, B. A. (2014). Clinical relevance of the proposed sexual addiction diagnostic criteria: Relation to the sexual addiction screening test-revised. Journal of Addiction Medicine, 8(6), 450-461. https://doi.org/10.1097/ ADM.0000000000000080.

Cloninger, C. R., Svrakic, D. M., \& Przybeck, T. R. (1993). A psychobiological model of temperament and character. Archives of General Psychiatry, 50(12), 975-990. https://doi.org/ 10.1001/archpsyc.1993.01820240059008.

Combs, D. R., Elerson, K., Penn, D. L., Tiegreen, J. A., Nelson, A., Ledet, S. N., et al. (2009). Stability and generalization of social cognition and interaction training (SCIT) for schizophrenia: Six-month follow-up results. Schizophrenia Research, 112(1-3), 196-197. https://doi.org/10.1016/j.schres.2009.04.010.

Desgranges, B., Laisney, M., Bon, L., Duval, C., Mondou, A., Bejanin, A., et al. (2012). TOM-15: A false-belief task to assess cognitive theory of mind. Revue de Neuropsychologie, 4(3), 216220. https://doi.org/10.1684/nrp.2012.0232.

Diener, E., Emmons, R. A., Larsen, R. J., \& Griffin, S. (1985). The satisfaction with life scale. Journal of Personality Assessment, 49(1), 71-75. https://doi.org/10.1207/s15327752jpa4901_13.

Ehrlé, N., Henry, A., Pesa, A., \& Bakchine, S. (2011). Assessment of sociocognitive functions in neurological patients presentation of a French adaptation of two tools and implementation in frontal dementia. Gériatrie et psychologie neuropsychiatrie $d u$ vieillissement, 9, 117-128. https://doi.org/10.1684/pnv.2010. 0252.

Etchepare, A., Merceron, K., Amieva, H., Cady, F., Roux, S., \& Prouteau, A. (2014). Évaluer la cognition sociale chez l'adulte: Validation préliminaire du Protocole d'évaluation de la cognition sociale de Bordeaux (PECS-B). Revue de Neuropsychologie, 6(2), 138-149. https://doi.org/10.1684/nrp.2014. 0301.
Godefroy, O., \& GREFEX. (2008). Fonctions exécutives et pathologies neurologiques et psychiatriques: Evaluation en pratique clinique. Marseille: DE BOECK UNIVERSITE.

Goodman, A. (2001). What's in a name? Terminology for designating a syndrome of driven sexual behavior. Sexual Addiction \& Compulsivity, 8(3-4), 191-213. https://doi.org/10.1080/ 107201601753459919.

Griffin, D., \& Bartholomew, K. (1994). Models of the self and other: Fundamental dimensions underlying measures of adult attachment. Journal of Personality and Social Psychology, 67, 430-445. https://doi.org/10.1037/0022-3514.67.3.430.

Grubbs, J. B., Camille Hoagland, K., Lee, B. N., Grant, J. T., Davison, P., Reid, R. C., et al. (2020). Sexual addiction 25 Years on: A systematic and methodological review of empirical literature and an agenda for future research. Clinical Psychology Review, 82, 101925. https://doi.org/10.1016/j.cpr.2020.101925.

Kessler, R. C., Adler, L., Ames, M., Demler, O., Faraone, S., Hiripi, E., et al. (2005). The world health organization adult ADHD self-report scale (ASRS): A short screening scale for use in the general population. Psychological Medicine, 35(2), 245-256. https://doi.org/10.1017/s0033291704002892.

Kraus, S. W., Krueger, R. B., Briken, P., First, M. B., Stein, D. J., Kaplan, M. S., et al. (2018). Compulsive sexual behaviour disorder in the ICD-11. World Psychiatry, 17(1), 109-110. https:// doi.org/10.1002/wps.20499.

Lecrubier, Y., Sheehan, D., Weiller, E., Amorim, P., Bonora, I., Sheehan, K. H., et al. (1997). The mini international neuropsychiatric interview (MINI). A short diagnostic structured interview: Reliability and validity according to the CIDI. European Psychiatry, 12(5), 224-231. https://doi.org/10.1016/ S0924-9338(97)83296-8.

Lezak, M. D., Howieson, D. B., Loring, D. W., Hannay, H. J., \& Fischer, J. S. (2004). Neuropsychological assessment (4th ed.). New York, NY, US: Oxford University Press.

Loas, G., Fremaux, D., \& Marchand, M. P. (1995). Etude de la structure factorielle et de la cohérence interne de la version française de l'échelle d'alexithymie de Toronto à 20 items (TAS20) chez un groupe de 183 sujets sains. Encéphale, 21(2), 117-122.

Mackinnon, A., \& Mulligan, R. (2005). Estimation de l'intelligence prémorbide chez les francophones. L'Encéphale, 31(1), 31-43. https://doi.org/10.1016/S0013-7006(05)82370-X.

Noel, X., Brevers, D., \& Bechara, A. (2013). A neurocognitive approach to understanding the neurobiology of addiction. Current Opinion in Neurobiology, 23(4), 632-638. https://doi. org/10.1016/j.conb.2013.01.018.

Roberts, D. L., Combs, D. R., Willoughby, M., Jim Mintz, Gibson, C., Rupp, B., et al. (2014). A randomized, controlled trial of social cognition and interaction training (SCIT) for outpatients with schizophrenia spectrum disorders. British Journal of Clinical Psychology, 53(3), 281-298 https://doi.org/10.1111/bjc.12044.

Rosenberg, M. (2015). Society and the adolescent self-image Princeton University Press.

Shamay-Tsoory, S. G., \& Peretz, J. A. (2007). Dissociable prefrontal networks for cognitive and affective theory of mind: A lesion study. Neuropsychologia, 45(13), 3054-3067. https://doi.org/10. 1016/j.neuropsychologia.2007.05.021.

So, R., Makino, K., Fujiwara, M., Hirota, T., Ohcho, K., Shin, I., et al. (2017). The prevalence of internet addiction among a Japanese 
adolescent psychiatric clinic sample with autism spectrum disorder and/or attention-deficit hyperactivity disorder: A crosssectional study. Journal of Autism and Developmental Disorders, 47(7), 2217-2224. https://doi.org/10.1007/s10803-017-3148-7.

Swineford, L. B., Thurm, A., Baird, G., Wetherby, A. M., \& Swedo, S. (2014). Social (pragmatic) communication disorder: A research review of this new DSM-5 diagnostic category. Journal of Neurodevelopmental Disorders, 6(1), 41. https://doi.org/10. 1186/1866-1955-6-41.

Taylor, E. M. (1959). Psychological appraisal of children with cerebral defects. Oxford, England: Harvard Univer. Press.

Ward, M. F., Wender, P. H., \& Reimherr, F. W. (1993). The wender Utah rating scale: An aid in the retrospective diagnosis of childhood attention deficit hyperactivity disorder. American Journal of Psychiatry, 150(6), 885-890. https://doi.org/10.1176/ ajp.150.6.885.

Warrington, E. K., \& James, M. (1991). The visual object and space perception battery. Bury St. Edmunds (UK): Thames Valley Test.

Wechsler, D. (2011). WAIS-IV - Échelle d'intelligence de Wechsler pour adultes - 4ème édition. Clinical Pearson.
Whiteside, S. P., \& Lynam, D. R. (2001). The five factor model and impulsivity: Using a structural model of personality to understand impulsivity. Personality and Individual Differences, 30(4), 669-689. https://doi.org/10.1016/S0191-8869(00) 00064-7.

van Wijngaarden-Cremers, P. J. M., \& van der Gaag, R. J. (2015). Addiction and autism spectrum disorder. In G. Dom, \& F. Moggi (Eds), Co-occurring Addictive and psychiatric disorders (pp. 193-204). Berlin, Heidelberg: Springer Berlin Heidelberg.

Wong, C.-Y. (2018). How does high-functioning autism (HFA) relate to addictive behaviors? A case illustration of two Chinese adults in Hong Kong. International Journal of Mental Health and Addiction, 16(6), 1394-1403. https://doi.org/10.1007/ s11469-018-9964-y.

World Health Organization (2018). International classification of diseases (11th Revision).

Zimmermann, P., \& Fimm, B. (2002). A test battery for attentional performance. In Applied neuropsychology of attention (pp. 110151) Theory, Diagnosis and Rehabilitation. 